\title{
Hybridization of Sociocultural Factors' Theory: Conditions for Learning in an Academic Community of Practice
}

\author{
Charles Adedayo Adebanji
}

Midrand Graduate Institute, Gauteng, South Africa

Foundation and academic support Programmes unit

Mishack Thiza Gumbo

Office of Graduate Studies, University of South Africa

\section{Doi:10.5901/mjss.2014.v5n1p205}

\begin{abstract}
This paper set out to explore the conditions required for learning in an Academic Community of Practice (ACOP) with Frenchspeaking students as stakeholders. English language acquisition was pivotal, among the other sociocultural factors they had to negotiate for academic learning to evolve. Utilising a single case study approach, semistructured interviews, focus group interviews, observation and narrative inquiry, it was found that three major sociocultural factors were determinants of academic learning in an academic community of practice comprising French-speaking students and other stakeholders. The language of learning and teaching (LoLT), academic acculturation and academic identity were instrumental to academic learning with constant redress among the sociocultural factors as French-speaking students progressed to full participation. The private tertiary education institution falls directly under the categorization of an academic community of practice, drawing on Otten (2009). Depending on redress among the three sociocultural factors, hybrids emerged as indices of learning trajectories of French-speaking students. When these three factors are in a state of redress, there is an emergent learning, depending on the extent of hybridization between the sociocultural factors.
\end{abstract}

Keywords: Academic Community of Practice, Culture, Sociocultural, Hybridization, Communities of Practice;

\section{Introduction}

The representation of foreign students in an academic community gives rise to a number of challenges which necessitate the formulation of a theory to comprehend their trajectory of learning. According to Kucking (2011, p.1), in a study that explored the integration of students at Twente, foreign students experienced their study overseas unpleasantly because of dissimilar cultural orientations. Kucking (2011) paved the way for an inquiry into factors capable of making the education of foreign students unpleasant. It also facilitated innovative thinking to discover a learning theory. Many researchers have attempted to explore the dynamics involved in the academic experiences of foreign students in the unusual culture (e.g. Hamann 2004; Marks 2005; Ogbu and Simons, 1998), but these studies were limited to secondary school education. They could not provide clear-cut theories to explain the dynamics of learning among foreign students. Researchers who attempted to offer explanations made contrasting comments on the dynamics of learning among foreign students in the novel society, possibly because the contexts under which their studies were conducted varied. Another reason may be linked to the complexities involved in learning in multicultural contexts. One of them was Marks (2005) who claimed that foreign students underperform academically compared to their indigenous counterparts. Marks said that in a number of countries, socio-economic factors significantly justify the underperformance of foreign students. However sociocultural factors were not significantly implicated in Mark's study. Marks' definition of sociocultural factors entails "community attitudes, aspirations and behaviours", which he said were insufficient to explain the low academic achievement of foreign students (Marks, 2005, p.927). Mark's study reiterates that prevailing school factors were vital in certain minimal cases that were investigated. We stretch the philosophy of Marks by exploring sociocultural factors to replace the notion of prevailing school factors in this study.

Among the notable theories that were proposed to comprehend the academic performance of foreign students in a disparate multicultural milieu was the Cultural Ecological Theory (CET) (Ogbu \& Simons 1998). Ogbu and Simons argue that foreign students had academic achievements because they willingly relocated to the unusual culture. They argue 
that students who were compelled to relocate to another country failed to succeed. Many researchers engaged the CET by arguing that it is unrepresentative of the events occurring among foreign students (e.g. Foster, 2005; Gilbert, 2009; Hamann, 2004), yet they did not discard the CET because it was taken to have merit after much criticisms. Their criticisms suggest that caution should be exercised when using CET to analyse the experiences of foreign students in another terrain. Consequently from the analysis that has been made in the literature (e.g. Foster, 2004), it seems that the appraisal of these researchers that Ogbu's explanation on foreign students' academic performance is one-sided could be considered as important. Particularly, Hamann (2004, p.403) argues that the CET is occasionally inaccurate because it does not take cognisance of the sporadic academic performance of foreign students who involuntarily relocated to another culture.

Sociocultural factors of significance to student learning and achievement are the language used to communicate the curriculum, acculturation to the academic community and mediated identity. Furthermore academic self-esteem among foreign students is seldom addressed. Drawing on Vandeyar (2010), the concept of academic identity is useful for drawing inference on how students develop academic self-esteem - a phenomenon which predicts the extent to which students take responsibility for their learning. Although many of the studies considered in this paper focused on immigrant students, there are concepts to borrow from them as we explore the situation of French-speaking students whose intentions centred on studying in South Africa without the intentions of settling down permanently.

Gilbert (2009, p.78), in an exploration of Ogbu's and Simons' thesis with respect to foreign students and school performance suggests that researchers "need to search for other theoretical explanations that may provide alternative perspectives in attempts to better understand the academic performance" of foreign students in the unusual society. All of the criticisms against CET occurred in terms of the secondary school experiences of foreign students in an unusual culture. Although the French-speaking students under study did not have any immigrant status in South Africa, it is vital to explore how they learn in a novel culture. The call of Gilbert reinforces our impetus to propose a theoretical framework that elucidates an understanding of the factors that enhance academic learning at tertiary level. Otten (2009) suggests that the tertiary academic institution be referred to as an Academic Community of Practice (ACOP). The setting where this study was conducted is similarly referred to as an ACOP to give it an undertone of a community with stakeholders as active participants. Stakeholders in the ACOP are students, lecturers, tutors, mentors, managers, deans of faculties and student advisors who relate with students from different countries at the research site. There is no known theory to understand how French-speaking students learn in their brief tenure in a novel multicultural terrain. To explore this identified gap we consider the three sociocultural factors at work in an ACOP namely language, acculturation and the negotiation of identity as suggested by Chow (2006).

To this end, we sought to answer the following research question: Does learning evolve when there is a hybridization of language, acculturation and mediated identity among foreign students in an academic community of practice? The argument is presented in this manner. First, we give concise background information on the intellectual context under which the study was conceptualized. Second, we explore the literature on the context of Legitimate Peripheral Participation (LPP) which is a depiction of how new entrants negotiate communities of practice (COP), to foreground it against the newly developed theory. Third, the research approach is presented. Fourth, the theory is discussed in connection with the findings and previous studies conducted. Finally conclusion is drawn to pinpoint the implications of the theory for educational practice.

\section{Setting the Scene}

French-speaking students, drawn from the foundation level to third-year degree programme, attending a private provider of Higher Education (HE) in the Johannesburg area of South Africa were the focus of this study. Their academic performance was explored under the sociocultural lens to decipher factors that enhanced or debilitated their capacity to learn at the academic institution. Academic achievement is presented as the demonstration of compliance with preset assessment criteria (Chow, 2006; Dillon, 2009). Among foreign students, academic accomplishment is not an easy task to explore because it depends on a number of manifest and hidden curriculum factors (Kurz Elliot Wehby \& Smithson 2010). Therefore the curriculum is viewed as presented, enacted and assessed curricula in an attempt to explore the research question of the study. The presented curriculum is the intended programme of study aimed-at for student learning. The enacted curriculum entails the facilitation approach that engages students with the curriculum. The assessed curriculum is the yardstick for measuring compliance with the presented and enacted curricula (Kurz et al., 2010). This was an area that the CET did not properly take into consideration despite its versatility at explaining the academic experiences of students in a foreign terrain. Therefore three sociocultural factors have been identified in this 
study to determine the accomplishment of foreign students aspiring to earn degrees in higher education. These include language, acculturation and mediation of identity (Chow, 2006).

Linguistic adjustment, the first sociocultural factor, is described as the requirement, briskness, and straightforwardness through which foreign students adjust to an environment dominated by the prevailing language of communication (Chow, 2006). Language is vital for the exchange of ideas, and for gathering daily facts concerning the new culture (2006, p.109). The acquisition of English is important in the briskness and straightforwardness through which French-speaking students adjust to the presented curriculum as well as the hidden curriculum they had to experience. Another dimension of language may involve the use of indigenous languages in the academic institution. This could constitute a hidden curriculum factor in an academic institution because its frequent use to communicate could lessen interaction among stakeholders (Adebanji, 2013). Consequently the ease at which French-speaking students comprehend English becomes an intellectual puzzle to unravel in the study.

Acculturation, the second sociocultural factor, is a broad term used to describe the extent of incorporation and adaptation of foreign students to their society of sojourn (Berry Phinney Sam \& Vedder 2006). It depicts the extent of belonging of foreign students to the academic institution and their acceptance of the academic and social cultures within the institution. We conceptualise acculturation as a measure of life satisfaction (Chow, 2007), and how the Frenchspeaking students of this study negotiate their pre-conceived cultures with the cultural tenets of the academic institution. Acculturation in this context is a hidden curriculum experience, and takes a different turn from the generally known acculturation to the mainstream society. The acculturation of French-speaking students to the academic institution was sought in the direction of academic acculturation to project their adherence to scholastic tenets and satisfaction with academic life.

The construction of identity, the third sociocultural factor, is taken to imply a mobile construct that spotlights the quest of French-speaking students to become academically unique. It denotes a dilemma of being incessantly shaped in harmony with the way they are situated in terms of previous experiences. It symbolises a phenomenon that is always influenced by background (Vandeyar, 2008, p.115). We adopt the description of Mana Orr and Mana (2009, p.450) that the negotiation of identities is a struggle, sandwiched between a conventional mainstream culture and a faction of novices from a dissimilar culture. It is a struggle because it creates a dilemma in terms of previously acquired cultural tenets and a confrontation with novel scholastic and non-scholastic cultural principles. Consequently the mediation of identities among the French-speaking students of this study is conceptualized as a hidden curriculum issue capable of impacting on their curriculum experience. Identity mediation is explored as academic identity, measured in terms of their satisfaction with the academic principles available to them. It is conceptualized as their capacity to develop academic self-esteem, vital for focusing their attention on learning.

\section{Theoretical Landscape}

We capitalize on the interconnectedness between the legitimate peripheral participation theory (Lave \& Wenger 1991) and communities of practice theory (Wenger, 1998) by announcing that there is a point of convergence between them. The convergence in principles creates an understanding of how learning evolves in a multicultural academic institution.

\subsection{Legitimate Peripheral Participation (LPP)}

Legitimate Peripheral participation initiates an understanding of how newcomers come into communities of practice. The opportunity to learn is provided by the legitimate involvement of students in the principles at work within the community. The associated challenges may spring up from the intricacies of using a common language of communication, the requirement to academically acculturate to the community and develop academic self-esteem, necessary to make them take responsibility for their learning. We employ the scholarly work of Lave and Wenger to propose an argument that the process of learning via enhanced involvement in communities of practice pertains to the students operating in the world of other stakeholders. These stakeholders may include lecturers, tutors and academic advisors.

Legitimate peripheral participation is the access to a typical ACOP, where students interact with more knowledgeable others (Reyes, 2007). The curriculum is conceptualised to extend beyond the frontiers of academics to other experiences which influence the presented and enacted curricula at the academic institution. It helps to understand the arrival of novice participants (French-speaking students) at the border of the ACOP and how they interact with stakeholders in a centripetal direction. Non-participation is a stance taken by participants as an act that defines their identity (Wenger, 1998, p.164). The process of legitimate peripheral participation is more about being involved in shifting 
dimensions of involvement in communal and academic endeavours that students engage with (Serpell, 2007, p.26). The shifting dimensions of involvement are taken in this study as the redress that intermittently takes place among the three sociocultural factors. For example the learning of English is as important as the requirement to develop academic selfesteem. Reflecting on the work of Merriam Courtenay and Baumgartner (2003, p.172), it is implied that this theory describes how French-speaking students grow into complete community members via interaction with the three sociocultural factors and the other stakeholders in the ACOP. Growing to become complete community members may entail refusal to interact and participate in certain actions of the community to create an identity. When this occurs, such students would be described as such (Wenger, 1998). This seems to explain why legitimate peripheral participation is the course of varying involvement and how the stakeholders in the community are identified (Serpell, 2007, p.26).

\subsection{Communities of Practice (COP)}

Communities of Practice are ubiquitous, applied to any social or academic setting (Lave \& Wenger 1991). According to social learning theorists, communities of practice offer a basis for participating in knowledge sharing between beginners and experts in the community (Li, Grimshaw, Nielsen, Judd, Coyte., \& Graham 2009). The three characteristics of COP are "domain", "community" and "practice" (Wenger, McDermott \& Snyder, 2002; Wenger, 2000). The domain defines the common environment and spells out the terrain that grants participants the fortitude to decide on things they have to share and how to offer their acquired skills to attain an identity. The community fabricates the communal basis that prompts learning via interaction with members of the community. The practice symbolizes an array of shared inventories of available capitals regarding information, ideas, proficiencies, and routes of resolving cyclical challenges (Li et al., 2009).

A basic concept in the COP framework entails knowing that the French-speaking students would not only learn as appropriately positioned members of the ACOP. They are rather regarded as dynamic learners within the community as they notice and show people in the domain what has been learnt. The learning that materializes among them would therefore become evident as they demonstrate proficiency in English, develop academic acculturation and academic selfesteem. These are conceptualized to provide them with the fortitude to take responsibility for their learning. It is Bandura's point of view that watching other people who are conversant with modes of operation in a community supersedes the gimmick of learning via trial and error (1977). We react to Bandura's argument by reiterating that watching other participants in the community may be dysfunctional. Bandura's views are not rubbished, however since Bandura's study was conducted in 1977, it becomes clear that circumstances may have changed and that the dynamics involved in the learning process of participants in an academic community of practice have become more complex. What is the significance of an onlooker's presence in an ACOP without the correct tools to participate in the activities therein? An onlooker's presence in the ACOP becomes inconsequential if for example, he/she does not speak the language of communication, has not gone through the adjustment process, and does not possess the knack of identifying with reasons for becoming a member of the ACOP. Issues of what we conceptualize as linguistic power relations could be important when the situation of an onlooker is considered, for effective engagement to evolve in the ACOP, drawing on the "continuity-displacement contradiction" dilemma proposed by Lave and Wenger (1991, p.115-116). It is expected that the French-speaking students would explicitly demonstrate proficiency in the use of English, and develop academic acculturation and academic self-esteem. They are speculated to be able to do this by confidently standing up to the upcoming challenges in manners that depict constructive learning beyond the ordinariness of observing stakeholders.

French-speaking students are perceived to gain right of entry to the ACOP by virtue of certain defining and eligibility factors stipulated in the community. Despite being marginally placed at the outset, they build up an identity via considerable interaction in the community with advancement towards total membership for reasons relating to a shared or committed realism via the language of communication (Lave \& Wenger, 2002, p.57). French-speaking students are thus at liberty to choose how to learn and what to learn. This freedom helps them to create an identity that describes the essence of their existence as members of the community. For ease of comprehension, the following model is proposed.

\subsection{Hybridization of sociocultural factors' theory}

This theory is presented as a mechanism of academic learning because of the intricate dynamics involved. It perceives that three forces are in a state of constant redress in an ACOP comprising stakeholders with different roles and responsibilities. These dynamics are the language of communication, acculturation to the ACOP and academic identity. As the French-speaking students enter the ACOP (see Fig. 1) they are compelled to learn English. As they interact with 
the other stakeholders, they tend to adapt to the mores of the community through integration. The degree to which they acculturate and negotiate their identities with the learning of English results in the formation of hybrids at points of intersection of the three sociocultural factors. At a definite intersection (Fig. 1), for example, a hybrid is formed by virtue of the concerted efforts of French-speaking students' engagement with the prevailing sociocultural factors in the community. At the point of intersection of the three sociocultural factors, hybridization is conceptualized to take place with the resultant hybrid formed, constituting the capital needed to initiate learning among French-speaking students in the community.

Figure 1: Hybridization of sociocultural factors

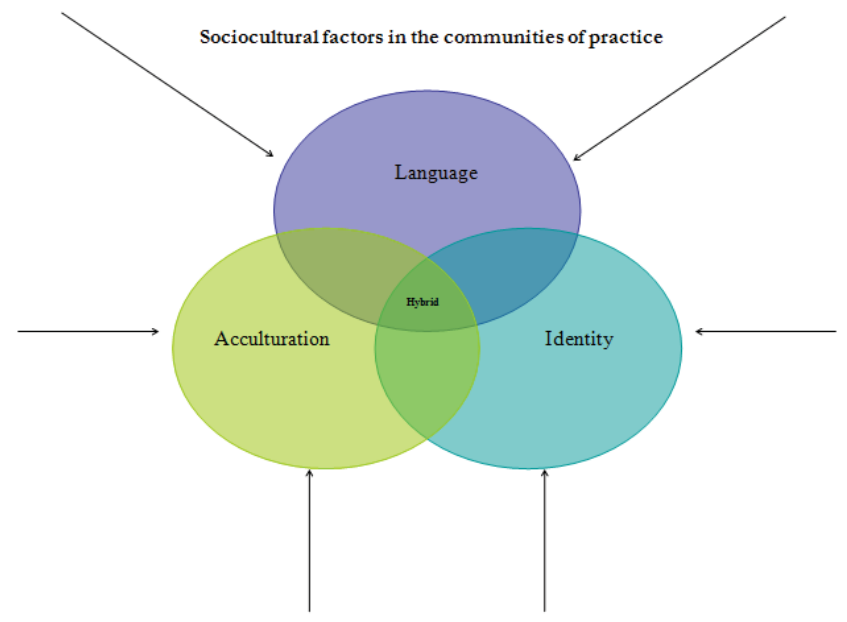

The deeper the engagement among the sociocultural factors, the bigger the size of hybrid formed. The magnitude of the hybrid is indicative of the quantum of learning. The learning that is envisaged to take place is theorized to occur in stages when entrants approach the community as legitimate peripheral participants. Learning may continue until the newcomers are capable of moving towards the centre of activities with redress depending on forces that are at play within the ACOP. The envisaged movement, a significant display of identity is through an interaction with more knowledgeable others. Nonacademic learning may evolve as a result of refusal to participate in learning certain mores and values, advertised by stakeholders in the community. For example, their refusal to learn the indigenous South African languages could be taken to imply another dimension of learning not to attain an indigenous linguistic identity. The learning in this context would only imply that they have decided to be recognized as not interested in learning the indigenous languages. Consequently, as long as they acculturate to scholastic injunctions, they are regarded as possessing academic acculturation and academic identity.

\section{Research Approach}

This study was qualitative and utilized narrative inquiry and case study of a private provider of higher education in South Africa. The data gathering process comprised in-depth semistructured interviews, and lecture room observations over a period of one and a half years before the study was conducted. A thorough observation of the research site and participants was conducted to capture the scenery of the research site. Our presence at the research site a year and a half before conducting the study enabled us to make decisions in terms of the research respondents and to familiarize with the site to earn the trust of respondents.

A total of 46 respondents were interviewed in this study. As specified by Creswell (2007, p.37) we gathered data in the site where respondents negotiated the issue or problem under investigation. The study sample was drawn from a private provider of higher education in the Johannesburg area of South Africa. Since the research was to explore the conditions under which learning takes place in an ACOP, 28 French-speaking students were purposively drawn from the pre-degree programme to the third-year degree programme. These comprised citizens of Cameroon, Gabon, the Democratic Republic of Congo (DRC), Chad Republic and Benin Republic in West Africa. Separate semistructured 
interviews were conducted with 5 lecturers who taught them, 5 French-speaking student advisors, the head of the Foundation Phase Course (pre-degree) and the Dean of the IT Faculty.

Additional data were collected in the first semester of 2013 at the research site via 2 focus group interviews with another cohort of French-speaking students from the pre-degree to the third-year degree programmes. A cohort of South African students comprised the third focus group interview, randomly selected from the community of students. Separate focus group interviews comprising 19 French-speaking students were conducted out of the previously interviewed French-speaking students that were interviewed one-on-one in 2012. Out of the 19 students, 13 of them were Frenchspeaking students, and the other 6 students were South African students. In 2013, 1 (one) French-speaking student was interviewed to complement the semistructured interviews conducted in 2012. This action was embarked upon to support the previously collected data in 2012, in an attempt to increase the depth of investigating this single case thus and enhance the validity of the study. A second round of semistructured interviews was conducted with the previously interviewed French-speaking students on areas that were not covered in 2012. Each interview lasted between 30 minutes to an hour, while the French-speaking students were daily observed during lecture periods and in their informal sitting positions during free periods and as they went back to their residence. The interviews were video-recorded and transcribed to ensure analysis of obtained data. The data were analysed using content and thematic analyses techniques as suggested by Elo and Kyngas (2008) and Braun and Clarke (2006) respectively. In this study, the academic institution shall be referred to as Montana College.

\section{Discussion of Findings}

The findings are discussed by considering emerging themes from the sociocultural lens, used to explore the research question. These include linguistic capital, sense of belonging, academic acculturation and academic identity, first phase conceptualization of cultural hybrid formation, learning via trial and error and lastly, the second phase conceptualization of cultural hybrid formation.

\subsection{Linguistic capital acquisition}

The importance of learning in English was voiced by a first-year French-speaking student (Barbra) from the DRC. She was studying Biomedicine at Montana College, sponsored by both parents in the DRC. Her utterance gave us the indication that French-speaking students brought the desire to learn in English from their home countries. This premonition was seen as the source of their tenacity to learn in a multiculturally disparate environment. Her narrative is presented:

Everywhere English is required, even in my country. English is one of the required languages at school, and for getting jobs. That is why I want to learn in English. As a French speaker, I would also like to speak in English. I want to be bilingual.

French-speaking students had to learn English at private English schools to gain access to Montana College. This was the first level of compliance with the set curriculum at Montana College. It is regarded in this study as the first phase of academic identity and compliance with the set curriculum. As Barbra began to learn English, she negotiated her French-speaking ability with English via the route of compromise to become bilingual. This attempt was a compromise to gain access to the academic culture of Montana College. Her interest to study in English opened her up to learning a new culture (academic culture). Her cultural tolerance seemed to predispose her to gain academic acculturation, evidenced by her comment in terms of being satisfied with life at Montana College:

This school is meeting my needs. My classmates are very friendly (nodding her head in affirmation). They talk to me, and I do talk to them as well. I am sure this school is going to assist me to achieve my goals.

We provide another example from Lara, a French-speaking student from Gabon, studying accounting:

I like this school because of my friends, and I live at the residence of the school. I have friends from South Africa. I have friends from Lesotho and Swaziland. They all help me with my studies, especially to learn English.

One of the third-year French-speaking students from Gabon (Anthony), interviewed in this research revealed the trajectory of gaining entrance to another culture via communication 
When I arrived here, I had to study English for 10 months before starting at this institution. I am a dedicated person. When I am doing something, it is either I do it or I don't. When I do what I am supposed to do, I do it the way it is supposed to be done. That is the best I could do to speak the English I am speaking now.

At third-year, Anthony could speak eloquently in English. He ascribed his astuteness in the use of English to his personality in terms of going out of his way to interact with more knowledgeable others to learn English - a requirement to learn in the COP. Anthony's experience in terms of interacting with more knowledgeable others corroborates the suggestion of Reyes (2007). According to Reyes (2007) learning ensues when the effrontery to associate with stakeholders in possession of requisite knowledge is sought by a beginner in a community of practice.

A number of hidden curriculum experiences became limitations to the French-speaking students in their quest to become integrated to Montana College. White South African lecturers' accents and their intermittent use of Afrikaans language to communicate the curriculum became challenges to them. They experienced acts of exclusion as far as communicating the curriculum was concerned. Incomprehensible accent was a hidden curriculum experience, among others, that delayed their understanding as far as the enacted curriculum was concerned. Bradley's experience at the foundation level with a white South African lecturer is provided:

I have a white lecturer, teaching student skills. At the beginning I couldn't hear what she was saying because she has a way of pronouncing words. It took me about 1 month to understand her accent. I always looked at the way she was pronouncing the words by looking at her mouth, but today I don't have that problem anymore.

The Dean of the IT Faculty (Ms. Lorenzo) revealed the experience of French-speaking students regarding accents. According to Ms. Lorenzo the fluency and rate at which lecturers spoke during facilitation exercises likely became inhibitory to learning among them. She reiterated the importance of appropriately pronouncing words by lecturers during learning facilitation. The effect of fluency and the rate at which lecturers spoke during learning facilitation could be more adverse on the French-speaking students, especially as they newly came to Montana College as legitimate peripheral participants. This could imply that their participation with the curriculum and the other stakeholders may be adversely affected. It could also imply that the rate at which they reached full participation was delayed. We present Ms. Lorenzo's concerns:

Sometimes the rate at which the lecturer talks also has an influence on the student's understanding of the module. At times the lecturers are not always South African, or English is not necessarily their first language. For example if they talk with an accent, it is also difficult for South African students to understand their English. It is also difficult for other foreign students to understand. We address this issue of pronunciation of the English language by sending the lecturers for training.

During the focus group interview sessions with the French-speaking students, there was a unanimous affirmation that pronunciation of words by certain lecturers was a challenge among the French-speaking students. We present Frida's comment (a third year French-speaking student) as a representation of the complaints lodged by the Frenchspeaking students in the focus group interview sessions. Frida's comment with respect to the accents of white lecturers revealed the severity of incomprehensible accents:

I still have problems with my lecturers, especially in terms of their accents. It is very difficult to hear what the white lecturers are saying.

Clara, a third-year French-speaking student from the DRC pointed to the incessant use of Zulu and Sotho (indigenous South African languages) as impediments to interacting with South African students. However she bypassed this challenge by adopting another method to learn English:

South African students speak Zulu and Sotho in class, and this does not help me to learn when I need help from them. They need to speak to us in English so we can learn from them. When I saw their attitude, I began to watch TV and read story books. My lecturers became my mentors. Tutors were also useful because they taught me English. I have enjoyed one-on-one contact with my lecturers during consultation sessions. I love this academic institution.

Clara's development of academic acculturation and academic identity gave her a sense of belonging that pushed her to find alternative ways of knowing and learning English from others. Her experience supports the argument of Wenger (1998:108) that there are other subsets of communities of practice that participants may engage for learning to 
evolve. South African students constituted dysfunctional communities of practice that did not assist Clara to learn English. Consequently she began to learn English through the media. However the combined experiences of Frenchspeaking students reveal the validity of Kucking's (2011) scholarship that the experiences of foreign students are not always pleasant overseas. These experiences support Serpell (2007:26) that the process of legitimate peripheral participation is more about being involved in shifting dimensions of involvement in communal and academic endeavours that students engage with.

\subsection{Sense of belonging, academic acculturation and academic identity}

The sense of belonging among French-speaking students, acquired via the process of gaining academic acculturation, predisposed them to negotiating their cultural academic capital which they brought from the French-speaking countries with the academic tenets at Montana College. Consequently, they were seen to have gradually negotiated their academic identity from the French-speaking countries with the curriculum stipulations at Montana College. An incidence is cited from the voluminous transcript of one of the DRC French-speaking students:

My aim is to focus on learning the English, come to terms with the academic environment and also to adjust to the situation at this school so as to learn and get my degree. South Africans are not friendly with foreigners because they speak their language but I focus on learning what I am supposed to learn at all cost.

Another valuable indication that learning English is vital was given by one of the third-year French-speaking students from Gabon (Jonathan). Jonathan found that the LoLT was his ticket to gaining access to the academic and social culture of the institution:

The students who fail their examinations fail because of the English language. The success of a French-speaking student revolves around knowing and understanding the English. If the level of understanding in English is good, and the level of commitment as a student is present in the French-speaking student it would be easy for success to be achieved. I enjoy interacting with English-speaking students, and this has helped me to learn English.

A brief analysis of his words points to the commitment required of French-speaking students to attain academic identity - learning English at all cost. This is interpreted in this study to imply academic acculturation and academic identity, which are inherently generated skills to achieve set goals.

The recognition of the requirement to speak and learn English at the school became an issue that was enforced to encourage the French-speaking students to learn English. This is because it has the capacity to allow them to gain access to the academic culture of the institution. The connection between language and sense of belonging is thus revealed as suggested by Yeh, Okubo, Ma, Shea, Ou and Pituc (2008). English language learning was pivotal to the academic and social survival of French-speaking students at Montana College. Understanding of English predisposes people to evaluate their mindset in terms of their acquiescence with the basic tenets of a community. Humans are thus given the freedom to voice their perception of a novel community via the tool of language. Language also places emphasis on how people negotiate their belonging in terms of wanting to be reckoned as part of a process or an institution. This finding makes the scholarly work of Chow $(2006, p .109)$ relevant that acquisition of the language of communication in the host society is the requirement and briskness through which foreign students comply with the tenets of academic activities.

Utilising the lens of Lave and Wenger (1991), an inability to speak eloquently in English hindered the participation and interaction of French-speaking students with the curriculum and the other stakeholders. According to Lave and Wenger (1991, p.49) the process of learning via enhanced involvement in communities of practice pertains to the entire person operating in the world of other people. This operation can be fostered by learning English. On the periphery of the ACOP the French-speaking students could not initially get involved with the world of the other stakeholders because of linguistic challenge, issues of character traits and sense of belonging to the ACOP. Consequently they could not initially engage with the other stakeholders as they newly came to the ACOP for academic learning to take place. Their inability to initially engage with the other stakeholders likely resulted in delayed transition from French to English. Findings in this regard agree with Lave and Wenger (1991, p.49) that the process of learning takes place through enhanced involvement of participants in communities of practice by the involvement of participants in the world of the other stakeholders. It is therefore affirmed that people describe their extent of association in terms of how they are affiliated to a belief system or disconnected from it. 


\subsection{First phase conceptualization of cultural hybrid formation}

The concept of hybridization of sociocultural factors as agents of learning is depicted for lucidity in an attempt to capture the detail of events at Montana College. In figure 2, a vivid look at the diagonals of the second inscribed rectangle gives a picture of the scenario at hand.

Figure 2: First phase of explanation of the concept of learning in a socioculturally diverse context

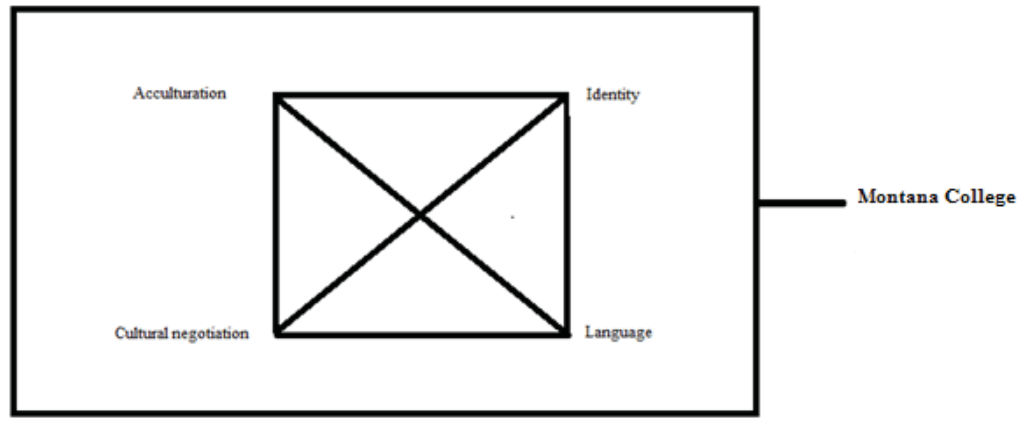

The larger rectangle depicts Montana College. The diagonal connecting acculturation to language is symbolic. It is a portrayal of the influence of language on acculturative tendencies among the French-speaking students. As it has been posited in literature that language opens the door for the process of acculturation to begin (Yeh at al., 2008), we argue that the learning of English, paved the way for the process of academic acculturation and academic identity to commence among them. As suggested by Yeh et al. $(2008$, p.784) that the acquisition of a prominent language orchestrates the ability to grow beyond the home cultures of foreign students to encapsulate another culture, so is it posited in this study that English language learning among French-speaking students at Montana College orchestrated a pedestal of negotiation between institutional academic culture and the inherent culture to excel, brought into Montana College from French-speaking countries. Based on this scholarship they were seen to possess the necessary sense of belonging to negotiate academic rigours. The process of developing academic self-esteem among French-speaking students is a function of how they associated and integrated into Montana College via the acquisition of English. English language acquisition is thus the fulcrum and catalyst of hybrid formation for academic learning to commence among them.

It is assumed that the inherent academic culture brought by the French-speaking students was potent enough, through their doggedness to learn English, until their attachment to home cultural tenets were temporarily fragmented to encapsulate the already existing academic culture at Montana College. This fragmentation is hypothesized to have created what we refer to as the "language-culture fragmentation interphase". It is conjectured that the formation of this complex was likely responsible for the initiation of hybrid formation to yield an amalgam of academic cultures as previously conceptualized elsewhere (Vandeyar 2008). The amalgam of cultures is argued to have initiated learning at Montana College, depending on the extent of redress among the other sociocultural factors namely academic acculturation and academic identity.

Another look at the second inscribed rectangle where the diagonal connecting cultural negotiation links up with identity reveals that, for academic identity to have been developed by the French-speaking students, they seemed to have entered into a zone of what we tag as "cultural-identity activation interphase". The birth of this complex was conceptualized to have resulted in the ingenuity of romanticizing the planned and enacted curricula until the right dimension of academic learning evolved. At this point they likely developed what we refer to as "academic self-esteem", needed to embrace the scholastic rigour to succeed. This "cultural-identity activation interphase" was likely stimulated into action via the procedural acquisition of English. A thorough analysis of the narratives of French-speaking students provides evidence that a concerted effort towards socialising with more knowledgeable others - a key requirement in the COP framework, presents the opportunity to interact with the other stakeholders and the curriculum of study. Interaction with the other stakeholders furthermore created the propensity to acculturate to Montana College by providing the opportunity to learn academic cultures on the ground. Interaction with more knowledgeable others likely provided the academic self-esteem required to demonstrate compliance with the curriculum of study. 


\subsection{Learning via trial and error}

By inference from the work of Wenger (1998, p.164), the experience of certain French-speaking students in terms of failing the English module was a measure of learning which they gathered to attain an identity to become university graduates through persistence. This learning was a kind of consolidation to become acquainted with the academic culture of tertiary education. Failure of English among them, particularly those who did not negotiate the pre-degree route was a demonstration of learning via trial and error. Therefore, the fact that some of them had to repeat the English module was a learning experience because they needed to undergo another process of renegotiation of academic cultures. This experience is presented from the narrative obtained from the Dean of the IT Faculty who said, "Some of the French-speaking students failed the English module twice or thrice before they could graduate". The Dean of the IT Faculty mentioned that, "failing the English module often prevented French-speaking students from graduating Cum Laude". Among those who failed the English "twice or thrice" before they passed, it is posited that they did not likely gather enough academic cultural assets capable of assisting them to demonstrate compliance with the assessed curriculum (e.g., association with more knowledgeable stakeholders in possession of the relevant linguistic capital).

It is suggested that the French-speaking students who had at one time or the other failed the English model needed to reach an equilibrium point represented at the point of intersection between language, academic acculturation, academic identity and cultural negotiation before a commensurate learning experience that stipulates the goals of the curriculum could be guaranteed (Fig. 2). It is thus theorized that they failed the English module "twice or thrice" because they probably lacked the correct dimension of intertwined scholastic cultures to reach the equilibrium point, likely situated at the point of intersection of the diagonals in Figure 2. In line with the argument proposed so far we assert that the language of communication is pivotal to the academic success of French-speaking students. We also suggest that linguistic acquisition is a link between academic and intercultural knowhow to integrate into the ACOP. Consequently we concur with the scholarship of Li, Grimshaw, Nielsen, Judd, Coyte and Graham (2009) about social learning theorists that communities of practice offer a foundation for participating in knowledge sharing between newcomers and professionals.

\subsection{Second phase conceptualization of cultural hybrid formation}

In Figure 3 we attempt to consolidate an understanding of the theory of hybridization of sociocultural factors as agents of learning. The arrows in Figure 3 refer to the French-speaking students approaching Montana College with their linguistic and acculturative tendencies to mediate their identities with the scholastic cultures of Montana College. As they approached Montana College, incessant redress likely began to emerge in terms of the acquisition of English, academic acculturation and academic identity among them, until hybrids were formed at the intersection of these sociocultural factors. At the points of intersection due to redress, learning is theorized to sporadically take place. As they began to comply with the tenets of the academic institution through the rigorous process of redress, they likely began to negotiate and renegotiate their stake until they reached full participation which likely resulted in learning to attain a set identity.

Figure 3: Second phase explanation of the concept of hybridization of sociocultural factors in an ACOP

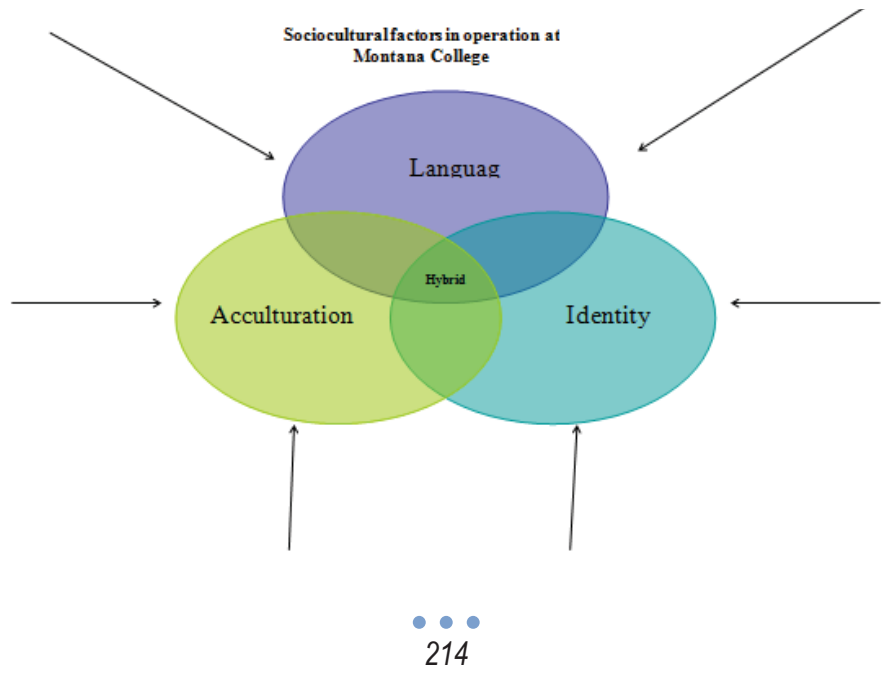


We agree with the suggestion of Wenger $(1998$, p.108) that in communities of practice, there are subsets of other communities of practice, instrumental to the overall involvement and learning trajectories of stakeholders. The requirement of French-speaking students to learn English, develop academic acculturation and academic identity via concerted efforts to interact with stakeholders at Montana College are taken as individual communities of practice which uphold their mission to earn degrees. These convoluted dynamics are regarded as evolving through the process of renegotiation among stakeholders and the curriculum of study. We present the process of renegotiation taken by a predegree student from the Republic of Benin in West Africa to become conversant with the tenets of academic culture as evidence. The redress she had to negotiate was likely assisted by her capacity to engage with the other stakeholders. The redress was in terms of changing her learning style by ceasing to translate curriculum content from English to French and back to English. It was common practise to translate curriculum content from English to French and back to English before module content could be comprehended by French-speaking students. Evidence is provided from Lynda:

\begin{abstract}
My friends help me to understand English and not to think in French. At the beginning, I used to convert from French to English and it took time for me to speak but now I am better. When I spoke English, I was a bit slow. In Benin, while in high school, I did English but it was only grammar that I did. I did not learn how to speak it.
\end{abstract}

In the same vein we present more narratives from French-speaking students to support our claim that Frenchspeaking students engaged in stages of redress to understand the curriculum. Ada, a first-year French-speaking student narrates her experience:

Sometimes, I do translate words from English to French, and back to English when it is too difficult to understand the words in English, I try to understand it in French. It is slowing my learning experience down a lot, but I have to do that for now until I improve. It is easier to write in English than to speak in English because I am shy in case I make mistakes.

Evidence that French-speaking students had a sense of belonging to Montana College is subsequently provided to support our claims by presenting a few narratives from them. A first-year French-speaking student from Gabon (Tatiana) compared Montana College to institutions in Gabon. Her expression symbolised academic acculturation and academic identity because satisfaction with academic life was depicted as she narrated her experience, drawing on Chow's (2007) scholarship. According to Chow (2007) the depiction of life satisfaction among foreign students in a multicultural milieu is indicative of satisfaction with life. The expression of a sense of belonging indicates that academic acculturation and academic identity have been developed by Tatiana, drawing on Yeh et al. (2008) and Vandeyar (2010) respectively:

This institution is meeting my academic needs because I can see improvement in some of my modules. In Gabon, you can't approach the lecturers like here in South Africa because, they are very different. In Gabon when you are talking with a lecturer, people may think you are engaged or you are going out together. Also my South African friends help me to improve my English.

Montana College employed a number of strategies to focus the attention of foreign students on developing the necessary connection to the curriculum. Prominent among those factors are small class size initiative, amiable studentlecturer relationship and the establishment of a language policy (Adebanji \& Gumbo, 2013). Based on the evidence in this study it is theorized that learning continues to occur as French-speaking students move centripetally into the core of activities. Their learning is sustained as they engaged with subsets of communities of practice. With persistent redress among the sociocultural factors, the magnitude of learning is conceptualized to vary from one French-speaking student to the other, and the dimension of learning is visible through the size of hybrid formed at the point of intersection of the sociocultural factors (see Fig. 3). Consequently, the research question that asks whether learning evolves when there is a hybridization of sociocultural factors has been answered.

\title{
6. Conclusion
}

The study has evolved a theory which attempts to add to the existing theories of learning in a sociocultural perspective. Wenger's (1998) theory of COP as well as the LPP theory, authored by Lave and Wenger (1991) were used to understand the trajectory of learning among French-speaking students. Vandeyar's (2008) study added to the obtained understanding that hybrids emerge when humans attempt to mediate their identities with the host society culture. The LPP model assisted in understanding the intricacies involved at the entry level of French-speaking students to Montana 
College. It also provided direction to the sequence of events traversed by them as they journeyed through the pre-degree to third-year degree programmes. Issues of the curriculum were split into the intended, enacted and assessed curricula as suggested by Kurz et al. (2010). These were the core ingredients relating to the essence of French-speaking students' belonging and participation in the activities of the curriculum. Other aspects of the curriculum, known as the hidden curriculum experiences were contemplated and found as determinants of the intended curriculum delivery and actualization.

The implication of these findings on education entails knowing that non-English-speaking students in a multicultural milieu should be adequately prepared to learn English before the commencement of degree programmes. Secondly they should learn English so that it would be capable of fostering their adjustment trajectories to the academic institution via the tool of interaction with more knowledgeable others.

\section{Recommendation}

It is recommended that tertiary academic institutions be furnished with the wherewithal that attempts to aid the peaceful coexistence of foreign and indigenous students by inaugurating a stern policy that ensures the right tool of communication. This could facilitate the integration of foreign students to the prevailing academic cultures, vital for learning to take place. However, one basic assumption made in this paper is that there were no traces of power dynamics among stakeholders. In a proper sense, this study's findings would have been consolidated by exploring the effects of power relations in terms of the "continuity-displacement contradiction" (1991, p.115-116), proposed by Lave and Wenger in their exploration of apprenticeship among artisans. There is a gap in terms of these dynamics, as was observed in the seminal work of Lave and Wenger. Lave and Wenger did not also elaborate on the intricacies of these forces at work in communities of practice. Without doubt, certain latent power dynamics were in operation at Montana College which hampered the brisk development of the three sociocultural factors, considered as agents of academic learning in this study. It is further recommended that an exploration of the possible power relations existing in an ACOP be made of paramount importance, in an attempt to elaborately expound the dynamics among the three sociocultural factors at work in a multicultural milieu.

\section{References}

Adebanij, C.A. (2013). Non-South African French-speaking students' curriculum experiences in a community of practice at a private tertiary institution. Ph.D Thesis, Unpublished. South Africa. University of South Africa.

Adebanji, C.A., \& Gumbo, M.T. (2013). Strategies employed by a private provider of tertiary education to create an enabling environment for non-English speaking students. U.S.-China Education Review, 3(7), 499-515.

Bandura. A. (1977). Social learning theory. New Jersey: Prentice Hall.

Braun, V., \& Clarke, V. (2006). Using thematic analysis in psychology. Qualitative Research in Psychology, 3, 77-101.

Bryman, A. (2008). Social research methods. New York: Oxford University.

Berry, J.W., Phinney, J.S., Sam, D.L., \& Vedder, P. (2006). Immigrant Youth: Acculturation,Identity, and Adaptation. Applied Psychology: An International Review, 55(3), 303-332.

Burden, R. (1997). Research in the real world: an evaluation model for use by appliedpsychologists. Educational Psychology in Practice, 13(1), 13-29.

Chow, H.P.H. (2006). Vietnamese-Canadian University Students in Regina: Sociocultural and Educational Adaptation. Canadian Ethnic Studies, 38(2), 104-112.

Chow, H.P.H. (2007). Sense of Belonging and Life Satisfaction among Hong Kong immigrants in Canada. Journal of Ethnic \& Migration Studies, 33(3), 511-520.

Creswell, W. (2007). Educational research: planning, conducting, and evaluating quantitative and qualitative research (3rd Edition). Pearson, Merrill Prentice Hall.

Dillon, J.T. (2009). The questions of curriculum. Journal of curriculum studies, 41(3), 343-359.

Elo, S., \& Kyngas, H. (2008). The qualitative content analysis process. Journal of advanced nursing, 62(1), 107-115.

Foster, K. (2004). The cultural ecological theory: John Ogbu's understanding of minority academic achievement, Intercultural Education, 15(4), 369-384.

Foster, K.M. (2005). Narratives of the social scientist: understanding the work of John Ogbu. International Journal of Qualitative Studies in Education, 18(5), 565-580.

Gottlieb, E. (2007). Learning how to believe: Epistemic Development in Cultural Context. The Journal of the Learning Sciences, 16(1), 535.

Marks, G.N. (2005). Accounting for immigrant and non-immigrant differences in reading and mathematics in twenty countries. Ethnic and Racial Studies, 28(5), 925-946. 
Gilbert, S. (2009). A study of Ogbu and Simon's thesis regarding Black children's Immigrant and non-Immigrant Status and school achievement. The Negro Education Review, 60(1-4), 71-91.

Hamann, T. (2004). Lessons from the interpretation/misinterpretation of John Ogbu's scholarship. Intercultural Education, 15(4), 399412.

Kucking, S. (2011). Internationalisation and the integration of international students at Twente. M.Sc. Thesis, Unpublished: University of Twente, Enschede.

Kurz, A., Elliot, S.N., Wehby, J.H., \& Smithson, J.L. (2010). Alignment of the intended, planned, and enacted curriculum in general and special education and its relation to student achievement. The journal of special education, 44(3), 131-145.

Lave, J. \& Wenger, E. (1991). Situated learning: Legitimate peripheral participation. Cambridge, UK: Cambridge University Press.

Lave, J., \& Wenger, E. (2002). Legitimate peripheral participation in communities of practice. In Li, L.C., Grimshaw JM, Nielsen C, Judd M, Coyte PC, Graham, ID 2009. Evolution of Wenger's concept of community of practice. Implementation science, 4(11), 1-8.

Mana, A., Orr, E., \& Mana, Y. (2009). An integrated acculturation model of immigrants' social Identity. The Journal of Social Psychology, 149(4), 450-473.

Merriam, S.B., Courtenay, B., Baumgartner, L., \& (2003). On becoming a witch: Learning in a marginalized community of practice. Adult education quarterly, 53(3), 170-188.

Ogbu, J.U., \& Simons, H. (1998. Voluntary and Involuntary Minorities: A Cultural-Ecological Theory of school Performances with some implications for Education. Anthropology \& Education Quarterly, 29(2), 155-188.

Otten, M. (2009). Academicus Interculturalis? Negotiating interculturality in academic communities of practice. Intercultural Education, 20(5), 407-417.

Reyes, R. III (2007). A collective pursuit of learning the possibility to be: The CAMP experience assisting situationally marginalized Mexican American students to a successful student identity. Journal of Advanced Academics, 18(4), 918-659.

Serpell, R. (2007). Bridging between orthodox Western higher educational practices and an African Sociocultural context. Comparative Education, 43(1), 23-51.

Vandeyar, S. (2008). Changing Student-Teachers' Beliefs and Attitudes in South African Classrooms, 113-126. In Weber, E. (Eds.) 2008. Educational Change in South Africa: reflections on local realities, practices and reforms. Sense Publishers.

Vandeyar, S. (2010). Shifting selves: Constructing and negotiating academic identities. South African Journal of Higher Education, 24(6), 914-934.

Wenger, E. (1998). Communities of practice: learning, meaning and identity (New York, Cambridge University Press).

Wenger, E. (2000). Communities of Practice and Social learning systems. Organization, 7, 225-246.

Wenger, E., McDermott, R., \& Snyder, W.M. (2002). Cultivating communities of practice. Boston: Harvard Business School Press.

Yeh, C.J., Okubo, Y., Ma, P.W., Shea, M., Ou, D., \& Pituc, S.T. (2008). Chinese immigrant high school students' cultural interactions, acculturation, family obligations, language use, and social support. Adolescence, 43(172), 775-790. 
